\title{
Intracranial Hypertension in a Patient with a Chiari Malformation Accompanied by Hyperthyroidism
}

\author{
Chang Hwan Pang, Soo Eon Lee, Chi Heon Kim, Chun Kee Chung \\ Department of Neurosurgery, Seoul National University College of Medicine, Seoul, Korea
}

The Chiari malformation is an infrequently detected congenital anomaly characterized by the downward displacement of the cerebellum with a tonsillar herniation below the foramen magnum that may be accompanied by either syringomyelia or hydrocephalus. Surgery, such as foramen magnum decompression, is indicated for a symptomatic Chiari malformation, although an incidental lesion may be followed-up without further treatment. Infrequently, increased intracranial pressure emerges due to hyperthyroidism. A nineteen-year-old girl visited our outpatient clinic presented with a headache, nausea and vomiting. A brain and spinal magnetic resonance image study (MRI) indicated that the patient had a Chiari I malformation without syringomyelia or hydrocephalus. An enlarged thyroid gland was detected on a physical examination, and serum markers indicated Graves' disease. The patient started anti-hyperthyroid medical treatment. Subsequently, the headache disappeared after the medical treatment of hyperthyroidism without surgical intervention for the Chiari malformation. A symptomatic Chiari malformation is indicated for surgery, but a surgeon should investigate other potential causes of the symptoms of the Chiari malformation to avoid unnecessary surgery.

Key Words: Intracranial hypertension $\cdot$ Chiari malformation $\cdot$ Hyperthyroidism $\cdot$ Headach

\section{INTRODUCTION}

The Chiari I malformation is an infrequently detected congenital anomaly characterized by the downward displacement of the cerebellum with a tonsillar herniation below the fora men magnum that may be accompanied by syringomyelia, hydrocephalus and increased intracranial pressure (IICP) ${ }^{6,14)}$. Patient may be asymptomatic or may have a variety of neurologic symptoms, including headache, neck pain, visual disturbance, vertigo, and ataxia ${ }^{1)}$. The most common presenting symptoms is headache. Surgery, such as foramen magnum decompression, is indicated for a symptomatic Chiari I malformation and Chiari I malformation with a syrinx, but incidental lesions may be followed-up without further treatment ${ }^{7}$.

There is no effective alternative to operative decompression for patients with a symptomatic Chiari I malformation ${ }^{12)}$. Howe-

- Received: March 23, 2015 - Revised: August 8, 2015

- Accepted: August 9, 2015

Corresponding Author: Soo Eon Lee, MD, PhD

Department of Neurosurgery, Seoul National University Hospital, 101

Daehak-ro, Jongro-Gu, Seoul 03080, Korea

Tel: +82-2-2072-2358, Fax: +82-2-744-8459

E-mail: leesea8081@hanmail.net

$\otimes T h i s$ is an Open Access article distributed under the terms of the Creative

Commons Attribution Non-Commercial License (http://creativecommons.org/ licenses/by-nc/3.0/) which permits unrestricted non-commercial use, distribution, and reproduction in any medium, provided the original work is properly cited. ver, the surgery is not always easy and may have complications, and patients should therefore be selected very carefully. Almost all of the patients who have a Chiari I malformation with a headache and a syrinx are offered surgical intervention to prevent permanent cord damage ${ }^{12)}$. In addition, patients without a syrinx are offered surgical intervention when a refractory headache appears or objective neurological abnormalities exist ${ }^{4,12,16)}$.

Headache is associated sometimes with IICP. However, IICP is associated with various causes, and the Chiari malformation may be an incidental finding.

We introduce a case of a Chiari malformation without a syrinx or hydrocephalus but with IICP that was caused by hyperthyroidism rather than by the Chiari malformation. The headache resolved after medical treatment for hyperthyroidism.

\section{CASE REPORT}

A nineteen-year-old girl visited our outpatient clinic complaining of a headache. The headache had started 3 months previously, followed by vomiting, and she could not concent rate on studying. A tingling sensation in the four extremities existed at the same time. She had lost $10 \mathrm{~kg}$ of her body weight during the 3 months (height $157 \mathrm{~cm}$, weight $73 \mathrm{~kg} \rightarrow$ $63 \mathrm{~kg}$ ). Brain magnetic resonance imaging (MRI) showed a normal-sized ventricle, but cerebellar tonsillar herniation grea- 
ter than $5 \mathrm{~mm}$, exactly $11 \mathrm{~mm}$ from foramen of magnum was detected that was consistent with a Chiari I malformation (Fig. 1). The syringomyelia was not accompanied by a whole spine MRI. The Chiari I malformation was suspected as the cause of the IICP.

A papilledema was detected on both eyes on a fundus examination (Fig. 2A), and severe disc swelling with peripapillary retinal nerve fiber layer swelling was observed.

While considering foramen magnum decompression for a Chiari I malformation with IICP symptoms, she was referred to our institute. Then, an enlarged thyroid gland was detected on a physical examination, and a thyroid function test was conducted. The initial thyroid function test showed an elevated free T4 level (4.44 ng/dL, reference: $0.7-1.80 \mathrm{ng} / \mathrm{dL})$, an elevated thyroid stimulating hormone (TSH) receptor antibody level $(2.3 \mathrm{IU} / \mathrm{L}$, reference: $0-1.1 \mathrm{IU} / \mathrm{L})$ and a decreased TSH level $(0.1 \mu \mathrm{IU} / \mathrm{mL}$, reference: $0.25-4.00 \mu \mathrm{IU} / \mathrm{mL})$. A thyroid ultrasonogram showed the diffuse enlargement of the thyroid with no hot or cold lesions, and the $99 \mathrm{~m}$-Tc scan's 20-minute uptake was $14.5 \%$. All of these laboratory results confirmed the diagnosis of hyperthyroidism, and the presence of the TSH receptor antibodies confirmed Graves' disease.

Therefore, the patient underwent medical management with
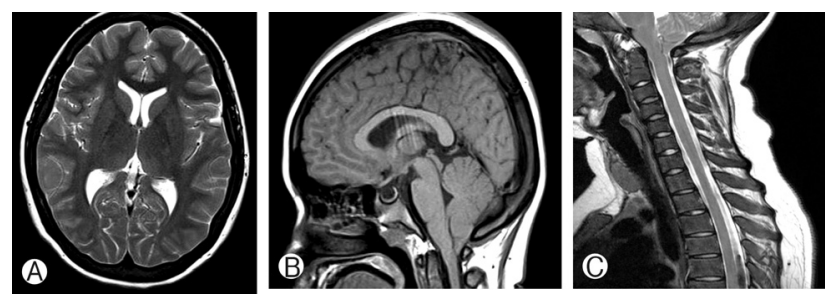

Fig. 1. MRI study. (A) T2-weighted axial brain MRI (MagnetomAvanto 1.5T; Siemens Healthcare, Erlangen, Germany). (B) T1weighted sagittal brain MRI (MagnetomAvanto 1.5T; Siemens Healthcare, Erlangen, Germany). (C) T2-weighted sagittal spine MRI (Ingenia 3.OT, Philips, Eindhoven, Netherlands). The brain and spine MRI showed the herniation of the cerebellar tonsil $11 \mathrm{~mm}$ from the foramen of Magnum consistent with a Chiari I malformation, without syringomyelia or hydrocephalus. The MRI also showed the incidental finding of empty sella. methimazole (10-5 $\mathrm{mg}$ ) and $40 \mathrm{mg}$ of propranolol (a beta adrenergic antagonist). After 2 weeks of medical management, she did not complain of headaches (Table 1). A fundus examination 3 weeks later showed that the fundus had returned to normal on both eyes (Fig. 2B). Her headache did not return during 6 months of follow-up. Consequently, she did not undergo a foramen magnum decompression.

\section{DISCUSSION}

The Chiari I malformation consists of the caudal displacement of the cerebellar tonsils into the upper cervical spinal canal, and it is commonly associated with syringomyelia or hydrocephalus. The most common symptom is headache, and other common symptoms include weakness or numbness, loss of temperature sensation, and unsteadiness ${ }^{8}$.

Cerebrospinal fluid (CSF) flow studies using cine phase
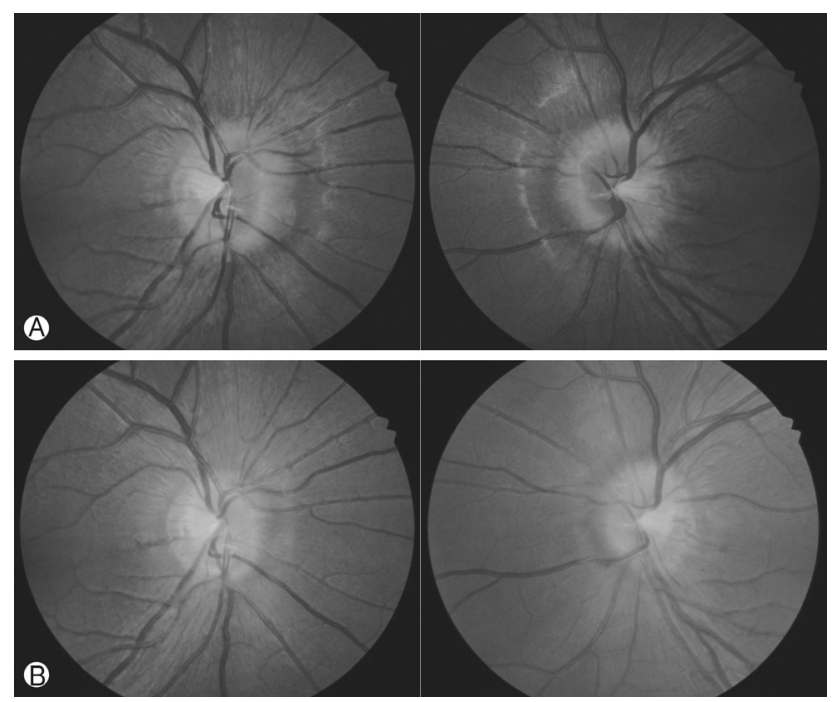

Fig. 2. (A) Initial opthalmologic examination. Both eyes showed severe swelling, with peripapillary retinal nerve fiber layer swelling. (B) An ophthalmologic examination was performed after three weeks of anti-hyperthyroidism treatment. Both eyes showed peripapillary elevations, without definite retinal nerve fiber layer swelling.

Table 1. Laboratory results of the thyroid function test

\begin{tabular}{lcccc}
\hline \hline & Pre-medication & Post-medication 2 months & Post-medication 3 months & References \\
\hline T3 & 606.38 & 132 & 114 & $60-190 / \mathrm{dL}$ \\
fT4 & 4.44 & 1.23 & 0.77 & $0.7-1.80 \mathrm{ng} / \mathrm{dL}$ \\
TSH & 0.01 & 0.1 & 1.08 & $0.25-4.00 \mu \mathrm{lU} / \mathrm{mL}$ \\
Anti TG antibody & 902.67 & & $0-70 \mathrm{IU} / \mathrm{mL}$ \\
Antithyroid microsomal antibody & 26.27 & & $0-30 \mathrm{IU} / \mathrm{mL}$ \\
TSH-receptor antibody & 2.3 & 2.5 & $<0.3$ & $0-1.1 \mathrm{IU} / \mathrm{L}$ \\
Clinical status & Thyrotoxic state & Euthyroid & Euthyroid & \\
\hline
\end{tabular}


contrast MRI have demonstrated that many children with symptomatic Chiari I malformations have an abnormal CSF flow at the foramen magnum ${ }^{9}$. Many clinical series advocate a posterior fossa craniectomy, including a suboccipital craniectomy and the removal of the $\mathrm{C} 1$ posterior arch, for the decompression of the cerebellum and the cerebellomedullary junction, along with an augmentative duroplasty for treating symptomatic patients with Chiari I malformations. There is a general consensus that the incidental discovery of asymptomatic patients with Chiari I malformations ordinarily does not make them candidates for surgical intervention ${ }^{13)}$.

There have been rare cases of hyperthyroidism with increased intracranial pressure; moreover, there has been no case of hyperthyroidism with a Chiari malformation. Coutinho et al. ${ }^{2)}$ showed a case of 31-year-old woman with clinical symptoms and laboratory confirmation of Graves' disease that presented as pseudotumor cerebri. Stern et al. ${ }^{15)}$ showed a case of 29-year old woman who had headache and laboratory confirmation of Graves' disease with occult hydrocephalus that became symptomatic during episode of thyrotoxicosis. Herwig et al. ${ }^{5)}$ showed a case of 32-year-old woman presenting with progressive symptoms of IICP and slight enlargement of the ventricle on CT scan. The underlying case was hyperthyroidism due to Graves' disease.

In hyperthyroidism, an increased cerebral blood flow with increased cerebral blood volume can cause IICP. IICP is associated with an elevated cerebral blood volume, with osmotic or vasogenic cerebral edema from the increased CSF outflow resistance at the arachnoid villi and with high cerebral venous pressure ${ }^{10)}$. Hyperthyroidism has been shown to increase the cerebral blood flow, which has been correlated with increased cerebral volume, and consequently IICP ${ }^{3,11)}$. There is also the theory that due to the increased general metabolic turnover associated with thyroid hormones, the CSF turnover and production is increased ${ }^{5)}$. However, whether the detailed mechanism of IICP in hyperthyroidism is due to the altered intracerebral hemodynamics with a secondary rise in the ICP is debated.

Headache, nausea, vomiting, and papilledema present as the primary features of $\mathrm{IICP}^{16}$. In the present case report, the patient complained of headache, which was caused by IICP, and the IICP was caused by Graves' disease or the Chiari I malformation.

Medical treatment for hyperthyroidism was started preferentially, and the presenting symptom abated without further surgical intervention for the Chiari I malformation.

\section{CONCLUSION}

If IICP is suspected in patients with Chiari malformations, other causes should be ruled out to avoid unnecessary surgery, especially in cases of Chari malformations without hydrocephalus or syringomyelia.

\section{REFERENCES}

1. Aitken LA, Lindan CE, Sidney S, Gupta N, Barkovich AJ, Sorel $\mathrm{M}$, et al: Chiari type I malformation in a pediatric population. Pediatr Neurol 40:449-454, 2009

2. Coutinho E, Silva AM, Freitas C, Santos E: Graves' disease presenting as pseudotumor cerebri: a case report. J Med Case Rep 5:68-69, 2011

3. Eichling JO, Raichle ME, Grubb RL Jr, Larson KB, Ter-Pogossian MM: In vivo determination of cerebral blood volume with radioactive oxygen-15 in the monkey. Circ Res 37:707-714, 1975

4. Haroun RI, Guanieri M, Meadow JJ, Kraut M, Carson BS: Current opinions for the treatment of syringomyelia and Chiari malformations: Survey of the pediatric section of the American Association of Neurological Surgeons. Pediatric Neurosurg 33: 311-317, 2000

5. Herwig U, Sturzenegger M: Hyperthyroidism mimicking increased intracranial pressure. Headache 39:228-230, 1998

6. Hwang GH,Kim GC, Jeong HJ, Sim YJ, Park YS: Arnold Chiari I malformation with tip-toe gait: a case report. Korean J Spine 10:38-40, 2013

7. Krieger MD, McComb JG, Levy ML: Toward a simpler surgical management of Chiari I malformation in pediatric population. Pediatr Neurosurg 30:113-121, 1999

8. Levy WJ, Mason L, Hahn JF: Chiari malformation presenting in adults: a surgical experience in 127 cases. Neurosurgery 12: 377-390, 1983

9. McGirt MJ, Nimjee SM, Floyd J, Bulsara KR, George TM: Correlation of cerebrospinal fluid flow dynamics and headache in Chiari I malformation. Neurosurgery 56:716-721, 2005

10. Ramadan NM: Headache caused by raised intracranial perssure and intracranial hypotension. Curr Opin Neurol 9:214-218, 1996

11. Ropper AH, Rockoff MA, Kennedy SK: Physiology and clinical aspects of raised intracranial pressure in Roper AH(ed): Neurological and Neurosurgical Intensive Care, ed3, New York: Raven Press pp 57-112, 1993

12. Schijman E, Steinbok P: International survey on the management of Chiari I malformation and syringomyelia. Childs Nerv Syst 20:341-348, 2004

13. Siasios J, Kapsalaki EZ, Fountas KN: Surgical management of patients with Chiari I malformation. Int J Pediatr 2012:640127, 2012

14. Sindou M, Chavez-Machuca J, Hashish H: Cranio-cervical decompression for Chiari type I-malformation, adding extreme lateral foramen magnum opening and expansile duroplasty with arachnoid preservation. Technique and long-term functional results in 44 consecutive adult cases - comparison with literature data. Acta Neurochir (Wien) 144:1005-1019, 2002

15. Stern BJ. Gruen R, Koeppel J, Aronson N, Krumholz A: Recurrent Thyrotoxicosis and Papilledemain a Patient With Communicating Hydrocephalus. Arch Neurol 41:65-67, 1984

16. Strayer A: Chiari I malformation: clinical presentation and management. Neurosci Nurs 30:90-96 2001 